\title{
WHY THERE ARE NO TOKEN STATES
}

\author{
ERIC MARCUS \\ AUBURN UNIVERSITY
}

\begin{abstract}
The thesis that mental states are physical states enjoys widespread popularity. After the abandonment of typeidentity theories, however, this thesis has typically been framed in terms of state tokens. I argue that token states are a philosopher's fiction, and that debates about the identity of mental and physical state tokens thus rest on a mistake.
\end{abstract}

\section{A}

ccording to one version of physicalism, everything is physical. The following thesis is of particular interest to philosophers of mind: every mental thing is also a physical thing. But which "things" are at issue? Objects, properties, events, states, processes, and facts among some others, have historically served as the metaphysical hooks on which physicalists have attempted to hang their various identity-theses. Over the last half-century, most of the debate has surrounded property- or typeidentity theories, and particular- or token-identity theories. But the thesis that mental properties or types are identical to physical properties or types has been largely abandoned on account of the "multiple-realizability" of mental types. ${ }^{1}$ To the extent that type-identity theory survives at all, it is often limited to a restricted class of mental types - to sensations, as opposed to propositional attitudes. ${ }^{2}$ But identity-theses stated in terms of particulars- token events, token states, and token processes-are largely taken for granted.

While philosophers of mind have paid a great deal of attention to the concepts of the mental and the physical, they have paid little attention to the "hook"-concepts. Rarely is a question raised about the differing contributions that the concepts of a state, event or process make to the truth-conditions of the identity claims that feature them. I have argued elsewhere that, given the nature of events, there are formidable obstacles to establishing identity claims between token mental events and token physical events. ${ }^{3}$ In this essay, I will defend a more radical thesis: There are no token states. Or, more precisely, there are no things that are both rightly called states and in the category of particulars. ${ }^{4}$ The 
type-token distinction, as it is generally understood by philosophers of mind, has no application to states. Therefore, a token-identity theory framed in terms of token mental states and token physical states cannot be true. (As I will indicate below, this view also undermines the idea that mental state tokens are realized or constituted by physical state tokens.)

In arguing against this particular ambition of physicalism, I do not thereby reject all of the theses commonly huddled under the physicalist umbrella. The denial of token-identity is compatible with the thought that there is no world outside the physical world. It is also compatible with the view that physical effects have complete physical causal histories. Physicalists sometimes talk as if the rejection of token-identity theory leads inexorably to either a fantastic supernaturalism or a deflating epiphenomenalism. But, as I have argued elsewhere, ${ }^{5}$ that is not so.

The argument of this paper will proceed as follows: In section I, I will frame the question that drives the debate concerning token-state identity, so as to make as clear as possible what is at issue. In section II, I will review and defend an approach to understanding the distinctive logic of state-talk, according to which the type/token distinction has no application to states. On this view, states (say, being red) are a species of universal. Universals of this sort are, as I'll put it, exemplified by particulars (as in the case of a red chair), but are not instantiated by particulars. Particular chairs instantiate the universal chair. Chair belongs to a different species of universal: types or sortals. The final three sections will be devoted to formulating and responding to three objections to this view. In section III, I will formulate and reply to an ordinary language response to this argument. Section IV formulates and replies to the methodological objection that we should insulate the metaphysics of states from the logic of state-talk. Finally, in section V, I will consider proposals that would identify token states with tropes or facts.

\section{FRAMING THE QUESTION}

Philosophers of mind use the expression 'mental state' to cover, paradigmatically, beliefs and desires, and all of what are commonly called propositional attitudes. The way of marking the category of state to be rehearsed in the next section shows why the type-token distinction has no application to beliefs, desires and the like. The distinction has no application, I will argue, because they are states. ${ }^{6}$

The question of whether mental states are token-identical to physical states is best understood as a question about the identity of particulars, as opposed to universals. Here's why we should think about tokens as particulars: In recent philosophy of mind, the type-token distinction gained currency when Davidson sought to defend a version of mind-body identity theory that rejected the reduction of mental types to physical types. Davidson needed a solution to the apparent paradox posed by the conjunction of three ideas: that such a reduction is impossible, that the mind is efficacious, and that all causation is physical. ${ }^{7}$ The doctrine of token-identity provides such a solution only if the relevant tokens are instances of both mental and physical types-if they have the ontological "thickness" characteristic of 
particularity. These particulars are causally efficacious (since they are instances of nomological, i.e., physical, kinds), and yet also mental (since they are instances of mental kinds). The concept of a token-state that I use here, then, is fundamentally tied to the notion of particularity. For if there are no such particulars, there can be no such instances. ${ }^{8}$

We can bring the particular/universal distinction into view with respect to events, where it has a relatively uncontroversial application (or is in any case no more controversial than the existence of universals). Yesterday, I crossed Columbus Avenue twice. There were thus two instances - two tokens - of a certain event-type, viz., crossing of Columbus Avenue. Event-types have instances-event tokens (or as I shall refer to them, simply events) — that are particulars. Events, unlike the types of which they're instances, themselves have no instances and are dateable. Eventtypes are not dateable because, being universals, they do not themselves begin or end at particular times - only their instances do.

Importantly, particulars are essentially countable. Consider once again events. Part of what makes a token street-crossing a particular is that it makes sense to count street-crossings. There are principles of identity and individuation for the type such that there can be one or two or however many token street-crossings. There is no such thing as a non-countable particular. ${ }^{9}$ If there are token states, then whenever I am in a state, there is an extra countable.

It is also important to note here that an event is a different particular than what is often called the subject of the relevant event. I am the subject of these two token crossings of Columbus Avenue; but I am not an event. The first street-crossing lasts about fifteen seconds, but I do not. As we consider whether the type-token distinction can be applied to states, we must also distinguish between the subject of the state, and the (supposed) token state itself. The question of whether there are mental state tokens thus needs to be separated from the question of whether mental states have subjects - or, as I will put it, the question of whether mental states are ever exemplified by anything. I will here assume that the answer to the second question is "yes" - that eliminativism is false. ${ }^{10}$ People are often in mental states. But the first question asks something else. A mental state token would not be an exemplifier of a mental state. Rather it would be a particular thing in its own right, a thing over and above the person who exemplifies the mental state type. My crossing Columbus Avenue is a particular distinct from me. In order to apply the doctrine of token-identity to states, there must be countables over and above me that stand to states as events stand to event-types. If there are no such particulars-and I will argue that there aren't - then there can be no application of the doctrine of token-identity to states.

With these conceptual and terminological issues at least partly clarified, we are ready to consider the reasons for thinking that there are no things that are both rightly called states and in the category of particulars - and so no token states. If these reasons are decisive, then questions about the identity of token mental states and token physical states do not get off the ground. 


\section{STATES, EVENTS, AND OBJECTS}

To advance a mind-body identity-thesis, one needs what I earlier called a hook. Though much of the debate about such theses in recent times has been explicitly concerned with event-identity, most of the examples that figure in such debates are of mental states. And, as I will argue in this section, there are no particular states, and hence it makes no sense to discuss whether mental states are the same particulars as physical states.

Events and objects are particulars par excellence. In this section, I will lay out the case for thinking that states are not particulars by showing that they lack the features of events and objects that plausibly explain their claim to particularity. Specifically, I will argue that states do not have principles of identity and individuation, and that only universals that have principles of identity are types, and thus only these universals have tokens. I begin this section by (A) reviewing a way of distinguishing states and events most clearly articulated by Anthony Galton in The Logic of Aspect. ${ }^{11}$ (Though, as we shall see in section IV, Galton misunderstands the significance of his own work. I will there consider and answer a Galtonian objection to my use of his work.) It will emerge from this discussion that whereas events are unitary, states are dissective. This section continues with (B) a discussion of a metaphysically salient difference between states and objects: The persistence of an object is a matter of the continued presence of a particular over time; the persistence of a state is a matter of a particular continuing to exemplify a universal. There are two further reasons for rejecting particular states: (C) states are negatable; whereas events and objects are not, and (D) event-nominalizations are count-quantified, whereas state-nominalizations are mass-quantified. Each of these points is ultimately tied to the fundamental reason why the type-token distinction has no application to states: states lack principles of identity and individuation.

A.

According to one recent and plausible way of thinking, event-talk arises because there is a distinction between perfective and imperfective verb aspect. ${ }^{12} \mathrm{~A}$ verbpredication with perfective aspect has a sense of completion; a verb-predication with imperfective aspect does not. Consider the verb-phrase 'to cross the street.' We can say both

(1) Jones crossed the street ${ }^{13}$

and

(2) Jones was crossing the street.

In (1), 'to cross the street' has perfective aspect (there is a completed street-crossing registered); in (2), 'to cross the street' has imperfective verb aspect (there is no completed street-crossing registered). (1) does not follow from (2), for Jones might have been trampled fatally by a bull before he finished his crossing. Events are the kinds of things that finish, and, as such, are the kinds of things that can remain 
unfinished. Wherever there are events that take time, we can always distinguish between perfective and imperfective verb aspect.

Now, in the case of states, no such distinction arises. Let us try to formulate a parallel distinction:

(3) Jones believed that the end was nigh.

(4) Jones was believing that the end was nigh.

Here (3) and (4) do not have the same relationship as (1) and (2). For (2) does not entail (1). But it's not clear how to interpret (4) so that it does not entail (3). Could Jones have been believing that the end was nigh yet never finished believing that the end was nigh? Even if we could somehow make sense of this form of words, it would turn out that for Jones to have believed this, in the sense of having finished believing it, will be something rather different than for Jones to have believed in the ordinary sense. For 'having believed,' in the ordinary sense, does not involve having finished doing or finished undergoing anything-believing is not the kind of thing that finishes. ${ }^{14}$

This way of characterizing events is a development of the Ryle-Vendler category of 'accomplishment,' which is contrasted with achievements (instantaneous events), activities (or processes), and states. In this essay I focus on the first and fourth category in this typology. The conception of an event, so understood, will be developed considerably over the course of this section. ${ }^{15}$

For the moment, this is the important point: Although we can use what are ordinarily stative verb-phrases to pick out events (i.e., in such a way that there is an analogue to the relationship between (1) and (2)), in so doing we change what it is that we're talking about. We are no longer speaking of states of belief, but rather are talking about certain (still obscure) events, to which we have extended the use of the word 'believe.' We are now talking perhaps about a certain contemplative episode in Jones's mental life. But the connection between this episode and his beliefs (in the ordinary sense) is tenuous. As will become clear, it is of the utmost importance in considering how correctly to apply categories such as "state" and "event" that one not change the subject. Here, changing the subject amounts to changing the semantics of belief-talk so as to make it conform to the model of event-talk. But this doesn't show that beliefs are events, only that we can use the term 'belief' to pick out events.

It is perhaps worth remarking here that this way of distinguishing events from states does not exclude the mental entirely from the category of events. Jones might be solving the math problem, for example, but yet not have finished solving it. Solving a math problem, then, is a kind of event, in my sense. And it does have tokens. My argument here, though it applies to all of what are commonly called propositional attitudes, has no application to mental event-types, of which Jones's solving of the math problem is an example. ${ }^{16}$

In the case of event-predications, then, there is a distinction between perfective and imperfective verb-aspect; in the case of state-predications there is not. This formal distinction has a material corollary. States are dissective; events are not. 
Galton puts the point in roughly the following way. Whenever a state obtains for a stretch of time, it also obtains for every sub-stretch of that time. In the case of an event, even though an event has phases, these phases are not events of the same type as the whole. ${ }^{17}$ If Jones believes that $\mathrm{p}$ throughout interval $\mathrm{i}$, then at any time during i, it will be true that Jones believed that $\mathrm{p}$. But if Jones crossed the street during a 30 second period, it is not true until after this period is over that Jones crossed the street. Events take time; states do not. And this is why (1) does not follow from (2) in the case above, and also why (3) does follow from (4)—so long as 'believing' is stative. ${ }^{18}$

But this way of distinguishing between states and events also provides reason for thinking that event-types have tokens, whereas states do not. Since events are unitary, they are countable. They have beginnings and ends; and so it makes sense to ask: How many? We can ask: How many times did EM cross Samford Ave. during September 2000. Because states are dissective, we ask not "how many?" but "for how long?" To the question "For how long has Jones believed that Nixon was a genius?" we might give an answer like "For two years." Along the same lines, we ask "For how long has the Jell-O been liquid?" and not "How many times has the Jell-O been liquid?" The applicability of the "how many?" question is tied to the countability of that to which it is applied. But, as noted in section I, countability and particularity go hand-in-hand. If "how many?" questions cannot be asked of states, then states are not particulars.

It might be countered that we can meaningfully ask how many times the Jell-O has been liquid. Similarly, we can ask: How many times has your hair been blond? How many times have you weighed over two hundred pounds? How many times have you wanted to punch that guy in the nose? How many times have you thought that your grandmother needs glasses?

But every such case falls into one of two categories. Either it is a case in which what is being counted is not really the state in question, or it is a case in which a word that typically is used to refer to a state instead refers to an event. I will discuss each sort of case in turn.

The Jell-O, hair, and weight examples are instances of the first sort of case. In these cases, what is being counted is not being Jello-O, having blond hair or weighing over two hundred pounds. It is rather gaining or losing (or perhaps gaining and losing) the relevant state. But I don't deny that one can count how many times the Jello-O has become (and then ceased to be) solid, or how many times Harlow dyed (and then dyed back or let grow out) her hair, or how many times Zero reached (and then fell below) two hundred pounds. For these are events, not states.

It might be countered that counting such events just is how (supposed) token states are counted. But someone who replies in this way must now explain why it is that event-types, such as dying one's hair or becoming solid, supply their own principles of identity and individuation to their instances, whereas supposedly analogous state-types, such as having blond hair or being solid, only supply principles of identity and individuation via some associated event-type. 
Here's what it means to say that event-types have principles of identity: a specific event-type $\mathrm{E}$ determines the conditions under which it is correct to say that an event $e_{1}$ is the same $E$ as event $e_{2}$. Here's what it means to say that event-types have principles of individuation: a specific event-type $E$ determines the conditions under which it is correct to say that the number of instances of $E$ that have occurred (typically, within specified spatiotemporal parameters) is X, for any number X. We implicitly or explicitly rely on such principles when we try to figure out whether the solidification of the Jell-O that occurred today (an event) is the same as the solidification of the Jello-O that occurred yesterday, or just how many times the Jell-O has solidified. States do not have such principles; and this is why a defender of state-tokens is forced to look to event-types to settle questions regarding the counting of supposed state-tokens. We ask how many times the Jell-O has been solid. To answer, we count how many times it has become solid. But this only serves to undermine the case for the intelligibility of the idea of a token state. States do not have principles of identity and individuation. Events (and objects) do. And because states do not have such principles, they are not particulars. I will return to this point.

For the moment, however, let us return to the second sort of case, and these examples: wanting to punch someone in the nose, thinking that one's grandmother needs glasses. If asked how many times I've wanted to punch that guy in the nose, I count certain episodes in my conscious life-for example, how many times I've derived pleasure from envisioning the prospect. If asked how many times I've thought that my grandmother needs glasses, I count how many times I've said it to myself, or how many times I've taken note of it, or how many times it has occurred to me, etc. But these kinds of mental episodes are not the topic of statements like: "I want to punch that guy in the nose" and "I think that my grandmother needs glasses." I might want to punch someone in nose because I've been paid to. If asked how many times I've wanted to, I may simply not find any instance of the sort of mental event-type that the question is asking me to count. 'Wanting' ordinarily figures in a state-predication; but when asked "how many times I've wanted to . . ." it refers to events. Similarly, when we speak of thinking that p, we are typically thinking of a state, one that need not manifest itself in any conscious episode of inner-speaking, or noticing. But if asked to count how many times I've thought that $\mathrm{p}$, this is precisely the sort of episode I look to. Both words are ambiguous between state and event readings.

In the case of event-predications, but not state-predications, there is a distinction between perfective and imperfective verb-aspect. This fact is significant, in my view, because it helps us to see the sort of particulars that events are. They are the sort of particulars that have beginnings, middles, and ends. And it is this fact about them that accounts for their specific form of countability. ${ }^{19}$ My claim is not that the particularity of every particular reveals itself, so to speak, in a distinction between predications with perfective and imperfective verb-aspect. But this distinction in the case of event-predication has pointed us towards the characteristic 
of types that explains their having tokens. Universals, such as event- and objecttypes, that are instantiated, as opposed to merely exemplified, have principles of identity and individuation.

B.

One cannot make a case for treating states as particulars by assimilating them to events. Can the particularity of states be established by assimilating them to objects? An object in the sense intended here is an item that's composed of matter and has no temporal parts. (I will not offer reasons here for preferring this conception of objects to the rival, "four-dimensionalist" conception. $)^{20}$ Upon reflection, few would argue that states are objects. First, the concepts of part-hood and composition have no univocal application to objects and states. Second, objects and states do not have the same relation to space. Objects compete for space with other objects. With the (possible) exception of the objects it composes or is composed by, an object cannot be at the same place and time as another object. But states do not compete for space with other states. We can put this point by noting that objects, but not states, take up space.

Though these differences may well shed light on the non-particularity of states, my focus will be on a different difference. Objects and states can both be said to persist, but what this comes to in each sort of case is fundamentally different. We can begin to appreciate this point by first considering the case of events, in which the notion of persistence does not so much as a get a grip. Persistence requires something fully present at one time, and still fully present at a later time. But events (at least non-instantaneous events) are not fully present as they occur. The whole walk across the street does not persist from the beginning of the walk to the end of the walk; for the walk across the street is not whole until the street has been crossed.

Both states and objects are, however, fully present when they exist or obtain, and so we can talk of persistence in both sorts of case. But because existing and obtaining are distinct, the sorts of persistence that characterize objects and states are also distinct. Here, on my view, is the difference. In the case of a state, e.g., Jones's believing that Nixon was a genius, the persistence of the belief is a matter of Jones's continuing to exemplify the same universal. In the case of an object, e.g., Jones himself, persistence is a matter of the continued presence of a particular over time.

Let's consider the opposing view - the view that the persistence of a state is the persistence of a particular, viz., a token that stands to a state-universal as events stand to types of events. Let's say that Jones believes at time t that Nixon was a genius. Call this mental state-token $n$, and its type N. Now if $n$ is an object-like particular, then there must be something that separates a case where $\mathrm{n}$ is replaced by another mental state token $\mathrm{m}$ also of type $\mathrm{N}$ at time $\mathrm{t}+1$, and a case where $\mathrm{n}$ persists through $t+1$. But our ordinary grasp of mental states gives us no basis to distinguish between these scenarios. (Resistance to relying on our ordinary grasp 
of metaphysical categories in philosophical argument will be discussed in section IV.) Thus, it is difficult even to understand a person who says: "Yes, Jones has always believed that Nixon was a genius, and in that sense Jones still believes what he used to; but I wonder whether his current belief is numerically identical with his former belief." The peculiarity of this question stands in stark contrast with corresponding questions regarding objects. For example: "I know you used to have kidneys; and you still have kidneys; but are those the very same kidneys with which you were born?"

The point is not that there would be no phenomenological difference between a scenario in which a token state was replaced by another and a scenario in which a token state persisted. The perplexing character of the question regarding the numerical identity of Jones's belief casts doubt on whether there is any prima facie reason for thinking we are even entertaining genuine possibilities when we attempt to contrast a token belief that Nixon was a genius persisting and such a token being replaced by another, type-identical token. If we know what a kidney is, then we know the difference between someone who has the same kidneys she was born with and someone who has new kidneys. Knowing what a belief is provides no corresponding understanding of the allegedly intelligible analogous contrast. Again, I have an explanation for this difference: states are universals that have no principles of identity.

To explain this difference between states and object-types (what are also often called sortals $)^{21}$ we should consider the distinction between principles of identity and principles of instantiation. ${ }^{22}$ The principle of identity for an object-type determines the conditions under which a particular instantiating the type persists. As Anil Gupta puts it, "the principle of identity for 'river' is the rule in virtue of which an object at a time (and a world) is the same river as an object at another time (or world)." ${ }^{23}$ The river we now call 'The Mississippi' is the same river that Mark Twain called 'The Mississippi' in virtue of such facts as the following: The earlier river runs through roughly the same places, is fed from roughly the same sources, empties into the same ocean as the current river, has done so continuously since the time of Huckleberry Finn, and so on. The principle of instantiation for river is the rule in virtue of which an object at a time instantiates the type, river. The Mississippi instantiates this type, because it is a large, natural stream of water that empties into an ocean.

There are principles of instantiation for both kinds of universals: types and states. But there are no principles of identity for states, only principles of instantiation. To say, for example, that "cat" determines the identity conditions for its instances, is to say that it follows from something's being a cat that it can persist through specific changes but not others. It does not, however, follow from something's being red that it can persist through specific changes but not others. "Red" determines the conditions under which an object is red, but not the conditions under which an object at a time is the same red thing as an object at another time. ${ }^{24}$ Similarly, object-types, but not states, have principles of individuation, which determine 
how many objects there are of a given type at a certain time (and place, perhaps). ${ }^{25}$ Because of this difference, there is no class of particulars that stands to states as objects stand to object-types. ${ }^{26}$

Here are a few objections that might be raised here:

Someone might have the following thought: "Perhaps the question regarding the numerical identity of a person's belief over time is odd. But we can, without oddness, ask about the numerical identity of the beliefs of several people. When Jones goes out for dinner with his friends, we can ask: how many instances of the belief that Nixon was a genius are present?" ${ }^{27}$ But we answer this question, if at all, by counting the number of people present who believe Nixon was a genius. People are, of course, countable. The answerability of this question provides no reason for thinking that there are individual belief-states. On the view I've outlined, there are several people, each of whom is in the same state: that of believing Nixon was a genius. The example provides no reason for thinking that the states themselves, as opposed to the people, are countable particulars.

If states have no principles of identity, then we would have no answer to the question: What is the difference between the state of being red and the state of being blue? Yet there is plainly is an answer. Similarly, there must be principles of individuation for states, since the question, "how many colors are there in the American flag?" plainly has an answer. But the difference between red and blue is not a difference in principles of identity, but rather a difference in principles of instantiation - a difference in the principles in virtue of which an object at a time instantiates the state of being red or being blue. And the countability of colors was never in question here. Principles of individuation provide counting-conditions for particulars. Colors are universals.

Talk of numerical identity in conjunction with the obtaining of a state is strained. Here's why: such talk has no application to states, since they lack principles of identity and individuation.

C.

There are two further reasons for denying that states are particulars of any kind. First, in the case of objects and events, their absence is not itself an object or event. The absence of a cupcake is not itself a particular on par with a cupcake. There is a sense in which there are non-cupcakes in the world, viz., all of the objects that are not cupcakes. But the absence of a cupcake is not itself an object. Thus we cannot ask the same questions about cupcake-absences as we can about cupcakes. "How many cupcakes are there in the box?" makes sense. Barring a very creative interpretation, "How many cupcake-absences are there in the box?" does not.

We can make the same point about events. Take the case of an event-type, say "crossing of Samford Avenue." A token of this event-type is a particular crossing of Samford Avenue. But the absence of such an event is not a particular event. If it were, then the question "How many times has Eric not crossed Samford Avenue?" 
would make sense. But this question does not make sense. How would one go about counting these supposed particulars? Say, over the course of a five-minute interval, I crossed this street twice. Now, how many times over the interval did I not cross it? Well, there are many Samford-street-crossings that I might have made during this interval, but didn't. I might have started a few moments earlier or later than I did, I might have crossed while sleeping, walking on my hands, rolling, zigzagging, staggering, or skipping. These are not the crossings I made. Are we to say that while I crossed the street twice, I also didn't cross the street many more times? As in the case above, there is a sense in which there are non-crossings, viz., all of the events that are not crossings. But the non-occurrence of a crossing is not itself a particular. There are many non-actual crossings. But there are no actual non-crossings - or rather, 'non-crossing' does not pick out a particular. So, as above, "how many?" questions make sense as asked about particular events, but not as asked about their absences.

If states were particulars, then one might expect to find the same asymmetry between presence and absence. But this is not what one finds. States are negatable. ${ }^{28}$ Consider the following pair of sentences, the first of which reports the presence of a state, the second of which reports the absence of a state.

(5) The table is red.

(6) The table is not red.

Unlike in the case of objects and events, any question that we can ask with respect to (5), we can intelligibly (if a bit awkwardly) ask regarding (6). Was the table red/not red in 1998? For how long has the table been red/not been red? Is the table still red/not red? It does not matter whether we are speaking of a state or the absence of a state. This suggests that the absence of a state is, if not itself a state, in any case ontologically on par with a state. The absence of objects and events are not object-like and event-like; but the absence of a state, it seems, is state-like.

It might be objected here that state-absences, such as being not-red, are not genuinely states at all. The reality of these negative properties is, after all, controversial. And if there are no such properties, then I cannot argue from a disanalogy with events and objects. But my point here does not depend on the reality of negative properties. It relies only on the fact that the very same questions that can be intelligibly asked and answered regarding the obtaining of a state can also be asked and answered regarding the failure to obtain of a state. Perhaps this is because the failure to obtain of a state is itself a state, but I am not committed to this view. Either way, there is a striking disanalogy with events and objects, where the very same questions that can be intelligibly asked and answered regarding the presence of an object or the occurrence of an event cannot intelligibly be asked and answered regarding the absence of an object or event.

I contend that the best explanation of this discrepancy is that objects and events are particulars, whereas states are not. As above, the explanation exploits the notion of a principle of identity: Particulars that persist through or take up time 
(objects and events, respectively) must be instances of kinds or types that determine principles of identity for these instances. ${ }^{29}$ In the case of both a goat and a tennis match, there are principles of identity associated with goats and tennis matches that determine the conditions under which goat $g$ or tennis match $t$ at one time is the same goat or tennis match as goat $h$ or tennis match $u$ at some other time. The difference between a collection of goat-composing molecules and $\mathrm{g}$, or between a set (in the non-mathematics sense, of course) of $t$ and $t$ itself, can best be captured by appealing to their different principles of identity.

But goat-absences are not associated with a principle of identity, for there is no such kind of thing as a not-a-goat. Similarly, there is no such kind of thing as a not-a-tennis-match. Among the non-goats there are: numbers, giraffes, collections of molecules, sets, galaxies, continents, events, and works of art, none of which share a principle of identity. "Is a the same goat-absence as b?" does not ask a determinate question because there is no principle of identity for goat-absences that would determine the answer to such a question. "How many goat-absences are there in the room?" fails to ask a question for the same reason. Particularity requires principles of identity and individuation. Particular-absences do not have such principles (i.e., goat-absences don't, tennis-match-absences don't, continentabsences don't, etc.). Hence, particular-absences are not particulars. Hence, the non-negatability of objects and events.

How are things different in the case of states? Simply put, states are not associated with principles of identity. The state picked out by 'is red' determines the conditions under which an object is red, but determines neither the conditions under which an object at a time is the same red thing as an object at another time nor the conditions under which there are two, as opposed to three, red objects in room at a given time. There is nothing that is "a red," in the way that there are lions, tables, and planets. There are red things, but red things are always things of particular kinds, instances of kinds, where kinds of things are associated with principles of identity. There are red tables, red paintings, red planets, red faces, etc. For something not to be red is thus not for it not to be $a$ red. ${ }^{30}$ What is at issue is not the absence of a particular, but just the failure of a particular to exemplify a certain universal. But the difference between the obtaining and non-obtaining of a property is not as ontologically stark as the difference between the presence and absence of a particular. At a time, there are just facts in virtue of which an object is red or not red. This is why the same questions can be asked about object's being red or not being red, as we saw above.

Events and objects are not negatable because events and objects have principles of identity. They have principles of identity because they are particulars. States are negatable because they don't have principles of identity. But if they don't have principles of identity, they aren't particulars, for principles of identity and particularity go hand-in-hand. The negatability of states, then, is deeply connected to the fact that states are not particulars. The non-negatability of events and objects, in turn, is deeply connected to the fact that events and objects are. 
D.

A final reason for rejecting the thought that there are token or particular states comes from a consideration raised by Mourelatos in his seminal "Events, States, and Processes." 31 There, he contrasts event-nominalizations and state-nominalizations. The former are count-quantified, the latter are mass quantified. For example, the event-predication,

(7) Jones crossed Samford Ave

is nominalized as

(8) There was a crossing of Samford Ave. by Jones.

The state predication

(9) Jones hates Smith

is nominalized as

(10) There was hating (or hate) of Smith by Jones.

Salient in this contrast is the presence of an article in the former case, and the absence of an article in the latter case. The presence of the article in the eventnominalization signals that the sentence is governed by an existential quantifier ranging over countables, i.e., particulars. Thus

(11) Jones crossed Samford Ave. three times.

is transcribed as

(12) There were three crossings of Samford Ave. by Jones.

The absence of the article in the state-nominalization signals that there is no quantifier ranging over countables at all. (11) is, in this respect, like

(13) There was water in the pot.

We say neither

(14) *There were three hatings (or hates) of Smith by Jones

nor

(15) *There were three waters in the pot

but rather

(16) There was much hating (or hate) of Smith by Jones and

(17) There was much (or little) water in the pot.

State-nominalizations are mass- rather than count-quantified.

It might be objected that although we have not heretofore count-quantified state-nominalizations, we could begin to do so. Our ordinary talk about states, the objection might go, is primitive; but we could gradually change that, developing a more sophisticated language that would pick out these neglected particulars. 
There is some truth to this objection. We could undoubtedly give a meaning to sentences such as (14) and (15). But in so doing, we have not made states or stuff countable, rather we've once again changed the subject. To say that there are three waters in the pot might be to say, for example, that there is some Perrier, some East River, and some Poland Springs in the pot. It also might be to say that there are three units of water of some determinate size. But in both cases, we have stopped talking about stuff and have instead begun to talk about something else: kinds in the first case and objects in the second.

A hating of Smith, in turn, might be something like a mental episode in which I focus on the qualities of Smith I hate, during which feelings of anger and the like pass through my consciousness. How many hatings of Smith I've undergone in the last month could then be understood as the number of such episodes that have occurred. But now 'hating' has taken on an event use (as 'believing' did above). For hatred, the state, is not an episode at all. It is not required for the truth of "Jones has always hated Smith" that Jones has been undergoing one long episode of this sort-it may be that Jones thinks of Smith very rarely. That we can use the word 'hate' to pick out a particular thus does not show that what we have heretofore called 'hate' is a particular or has particular instances. Rather, when we use the word 'hate' to pick out a particular we have, as above, simply begun to use 'hate' in order talk about a certain kind of event and its instances. We have, in other words, changed the subject. Thus, although we are not forbidden from inventing a token sense for 'hate,' it is just that-an invention. It doesn't show anything about the metaphysics of hate, the state.

In appreciating this point, it is important to keep in mind the point made above concerning the topic of this essay. My claim is not that no mental item is countquantified. Smith might have experienced a longing for peas today several times. He may have felt a pin-prick of jealousy six times, and each time been embarrassed at his own feelings. But these experiences, feelings and reactions are mental events. As above, we can also make sense of a question such as "How many times has Smith been gloomy today?" even though being gloomy is a state. In such a case, we count how many times he has become (and then later ceased to be, perhaps). Becoming (and later ceasing to be) gloomy are countable types. Being gloomy is not.

Event-nominalizations are count-quantified; state-nominalizations are not count-quantified. A plausible explanation for this discrepancy is that events, because they have principles of identity and individuation are countable, and states, because they have no such principles, are not. But if states are not countable, then they are not particulars.

We have seen that states are not particulars of any familiar type, and that there are good reasons for thinking that states are not particulars of any type at all.

(A) Whereas events are unitary, states are dissective.

(B) The persistence of an object is a matter of the continued presence of a particular over time; the persistence of a state is a matter of a particular continuing to exemplify a universal. 
(C) States are negatable, events and objects are not.

(D) Event-nominalizations are count-quantified; state-nominalizations are mass-quantified.

These points can all be explained by the fact that event-types and object-types have principles of identity and individuation, whereas states lack them. And, lacking such principles, states do not have instances, whereas event-types and object-types do. Thus, there are no things that are rightly called states and in the category of particulars. And if there are no particular states, then there are no token mental states or token physical states. We can ask about the identity of mental and physical states, but we are then asking about the identity of mental and physical properties. Token states are, I contend, a philosopher's fiction. If mental and physical properties are not identical, there is no sense in which mental states are identical to physical states.

\section{RESPONSE FROM ORDINARY LANGUAGE}

The thesis that there are no token states is apt to roil, both because it pulls the rug out from under a popular physicalist thesis, and because token states have become staples in the conceptual tool-kit of today's philosopher of mind. Resistance is likely to come in three forms. First, it might be argued that much of our ordinary talk about mental states presupposes that there are token mental states. Second, it might be argued that the facts about the grammar of state-talk just reviewed should have no bearing on metaphysics. Third, it might be argued that states are tropes or facts, and therefore particulars. Responding to these three objections occupies this and the following two sections.

I've found that many philosophers react to the claim that there are no token states with incredulity. "It's just obvious that there are token states; we speak of them all the time. And were philosophical argument to show that there are none, then much of what we ordinarily say is simply false."

But the most typical invocations of mental states do not, on the surface at least, refer to supposed mental-state tokens. We talk, for example, of Jones continuing (or not continuing) or coming to (or not coming to) believe a certain proposition. But if I say that Jones believes that Nixon was a genius, I attribute to him a state that I might also attribute to someone else. ("Smith thinks so as well," I might add.) I no more attribute a token state of belief to Jones when I say that Jones still believes that Nixon is a genius than I attribute a token state of solidity to the table if I say the table is still solid. This claim contains a singular term, which refers to an object, and predicate, which refers to a universal. At first blush, there appears to be no reason to treat mental state-ascriptions differently. (Of course an advocate of tropes holds that properties are particulars, and thus that we do attribute a token state of solidity to a table when we say it's solid. I will consider this objection in section V.)

My opponent will no doubt cite sentences that are more plausibly interpreted as referring to token mental states. The best examples are causal statements involving mental states: 
(17) Jones's belief that Nixon was a genius upset Jones's mother.

(18) Smith's desire to live in a warm climate eventually led her to move to Florida.

It was not the relevant belief and desire types that had these effects, it seems. It was Jones's belief, and Smith's desire that are efficacious. Jones's desire to live in a warm climate did not lead Smith to move; and Smith's belief that Nixon was a genius did not upset Jones's mother.

Let us consider two possible models for understanding $(\mathrm{R})$ and $(\mathrm{S})$ :

(19) Jones's exploding appendix ruptured his spleen.

(20) Smith's fair complexion led to many painful sunburns.

Now in the case of both (19) and (20), we can say what we said about (17) and (18): It wasn't the general event-type "explosion of appendix" that caused the rupture of the spleen, it was the token rupture of Jones's appendix that was causally efficacious. Similarly, it wasn't fair complexion simpliciter that led to Smith's sunburns; rather it was Smith's fair complexion.

Now, there is also a difference between (19) and (20). In the case of (19), the cause is a particular: the explosion of his appendix. But in the case of (20), the cause does not seem to be a particular at all. Smith's complexion, like his weight, his eye color, and his shoe size, is a property, and, as such, can be exemplified by others as well. Smith gets sunburned easily because he has a fair complexion. It is in virtue of his having this property that he sunburns easily. But this provides no reason for thinking that his complexion is a particular, on the model of an appendix or a token appendix explosion. To say that Smith's fair complexion is a partial cause of his sunburns is just to say that Smith has a property in virtue of which he gets sunburns. It is not to say that there is another thing (viz., his complexion) that leads to his getting sunburns. ${ }^{32}$

We saw above that one motivation for treating Jones's belief as a particular is that it is Jones's belief that is causally efficacious. But one can recognize this latter fact along the lines of our analysis of (20) above. Jones upset his mother because he instantiated a certain universal, viz., believing that Nixon was a genius. This property did not somehow cause the upset all by itself, without Jones's participation, as it were. But there is no need to postulate, in addition to the property of believing that Nixon was a genius and the thing that has the property, Jones, yet another thing, the token mental state. (It might be objected here that we do need another thing beyond Jones to account for the causation: the fact that Jones believed Nixon to be a genius. Facts will be discussed in section V.)

Ordinary causal statements are thus at best neutral with regard to the particularity of states. They provide no evidence that we speak, or attempt to speak of tokenstates all the time. The view that there are no token-states has thus not been shown to render much of what we ordinarily say false. And the considerations raised in section II continue to exert their full weight. ${ }^{33}$ 


\section{RESPONSE AGAINST ORDINARY LANGUAGE}

I now move to the second of our three objections. This objection, which comes in two forms, springs from the thought that metaphysics should not or need not take its cue from what we ordinarily say or the grammar we use to say it.

Galton, whose work I have made extensive use of in the argument above, makes the following remark on the intended significance of his distinction between events and states:

The distinction between states and events is not a distinction inherent in what goes on, but rather a distinction between two different ways we have of describing it. The same objective situation may be reported either by the sentence Jane was swimming or by the sentence Jane had a swim; the first sentence presents the situation as a state-of-affairs, the second presents it as the occurrence of an event. ${ }^{34}$

According to Galton, the grammatical or logical differences between event- and state-language lack what I'll call ontological transparency. Galton uses the expressions 'what goes on' and 'objective situation' in a way that is supposed to be neutral between event and state interpretations. A physicalist might take up Galton's thought in the following way: "Even if we were to accept your conclusion, it would only show that the metaphysical categories implicit in commonsense talk of the mind and the body are not well-suited to stating certain physicalist truths. If the language of states, events, objects and facts isn't up to this task, we need only develop a language that is. After all, event-, state-, and object-talk just reflect certain arbitrary and idiosyncratic ways of conceptually carving up the contents of the universe. And the basic thought behind physicalism is just that the universe is entirely physical. The language of a neutral, non-anthropocentric metaphysics would allow us to express this thought."

Until such a language is developed, this proposal is impossible to judge definitively. Coining phrases such as 'objective situation' with the intention of talking in a way that is neutral between an event- and state-reading is all well and good; but such phrases are of no help to the physicalist until she has given them a meaning. Do objective situations have temporal parts, or do they persist through time? Are they dissective? Are they negatable? What, roughly, are their identity conditions? Do objective situations have identity conditions as such, or do they have identity conditions qua particular kinds of objective situations? What kinds of objective situations are there? How do sentences that apparently refer to objects, states, and events refer to objective situations? What are the objective situational truth-conditions of these sentences? Such questions must be answered, or at least plausibly rejected, by any theory that uses terms such as 'objective situation' in order to spell out the thesis that the contents of the universe are entirely physical.

Meanwhile, I recommend suspicion. In the absence of answers to these questions, it's hard to know how to understand the basic physicalist thesis that "the contents of the universe" are entirely physical. For what we mean by "the contents of the universe' is just the objects and kinds of objects it contains, what happens to 
these objects, and the states these objects are in. The thought that there is, behind this world of appearances, a different world, structured according to heretofore unconceptualized metaphysical categories, is notoriously obscure. It is also something of an incongruous backdrop for a physicalist view of the world, since these obscure metaphysical categories are not even the kinds of things that physical science as currently practiced is equipped to discover. Furthermore, even if we were to develop such a language and use it to state a tenable physicalist thesis, it remains doubtful that such a doctrine should count as a vindication of physicalism as currently understood. Since this doctrine is not one we can currently conceive of, it cannot possibly be the doctrine that many currently find so appealing. And insofar as our physicalism claims that mental states are token-identical to physical states, the arguments presented here show that physicalism isn't true. Finally, if there really are no states, then questions about the identity of physical and mental states are in any case based on a confusion - albeit a different confusion than I contend they're based on. In either case, the doctrine of token-identity should be rejected.

Let us look at a second form this objection-that metaphysics should not or need not take its cue from what we ordinarily say or the grammar we use to say it - might take. The first objection involved the idea that ordinary language is not ontologically transparent, that our basic conceptual categories do not correspond to the world's basic metaphysical kinds. A more moderate response along the same lines would be that although the grammar of state-, event-, and object-language is ontologically transparent, it doesn't settle all of the questions one might have about states, events and objects. Remember, consideration of the differences between objects and states led us to an important reason for doubting the idea that states are particulars. In the case of objects, there is a principled distinction between persistence and substitution of another of the same kind; for states there is no such principled distinction. But according to this objection, although common sense leaves questions open about numerical identity in conjunction with states, there is no reason why some further inquiry could not finally settle them. Grammar commits us to the existence of states; now we need to discover their nature.

But what discipline would such an inquiry belong to? What principles would guide it? There is no science of states per se. So far as I can tell, a scientific inquiry into the persistence of states could be nothing other than a scientific inquiry into the conditions under which objects continue to possess, or fail to continue to possess, properties. Until and unless we arrive at a grand unified theory of everything, such an inquiry will necessary be wildly heterogeneous. Again, it makes absolutely no difference to any of our explanatory practices whether we say that states persist or are continually replaced. The allegedly new information that Jones's belief that Nixon was a genius is not token-identical to his former belief gives us no explanation of anything.

The thought that event- and state-talk lack ontological transparency is an expression of a familiar tendency in philosophy. It suggests that there is a noumenal realm that we can grasp, if at all, only by peeling away these superficial grammatical categories. Given the difficulty in making any such view intelligible, we ought to 
search for a very compelling motivation before offering one. The urge to establish a token-identity thesis, in my view, provides no such motivation.

\section{TROPES AND FACTS}

Let us now consider a final pair of objections to the argument of section II. One source of opposition to the line of thought I've here advocated will come from a proponent of tropes. ${ }^{35} \mathrm{~A}$ trope is an entity whose nature is exhausted by its being the instance or instantiation of a property at a time and place (or inhering in an object at a time). According to a trope theorist, to say that my car is white is to say that my car stands in the relation of possessing (or perhaps of being partly composed by) another particular, viz., an instance or instantiation of whiteness. If my car and your car are white, regardless of whether they have the same colortype,$^{36}$ they have different color-tokens. Mental-state tokens, a trope theorist might claim, are just tropes.

My reply to the objection from tropes just is the argument of section II, for tropes just are token states. If that argument works, then there are no such things as tropes. Consider, by way of reminder, the argument of Section II.B: According to trope theory, if a car is white, a particular white trope is present. But, if tropes are particulars, then there should be some principled way of deciding between the following descriptions of this scenario: (i) The car's white trope persists throughout the twenty-four hour period; (ii) the car's white trope is immediately replaced at every moment during the twenty-four hour period by another (exactly resembling) white trope; (iii) there is a pair of white tropes taking turns succeeding one another over the course of the day; (iv) there is a trio of white tropes succeeding one another over the course of the day; and so on. ${ }^{37}$ The problem, again, is that being white is not associated with a principle of identity. There may be such a thing as this car's whiteness, but it is either the specific shade of white (a universal), or the fact that this car is white, which is neither a universal nor a particular — or at least not a particular in the sense at issue in debates over token-identity. I will expand on this latter point presently.

Before moving to facts, however, it is perhaps worth mentioning that tropes would not, in any case, be of help to the advocate of the doctrine of token-identity. For a trope metaphysics is hostile to identity statements that cross distinct domains. If tropes correspond to property-time-place (or property-time-object) triples, then trope $\mathrm{a}$ is identical to trope $\mathrm{b}$ only if the properties in question are identical. An instance or instantiation of whiteness cannot be identical to an instance or instantiation of blueness, since white and blue are different colors. Similarly, an instance or instantiation of a mental property cannot be identical to an instance or instantiation of a physical property, since mental properties are not identical to physical properties. ${ }^{38}$ (And if mental properties are physical properties, then the debate over token-identity was misguided from the start. For physicalists looked to the doctrine of token-identity for consolation in the wake of the failure of the doctrine of type-identity.) So, on the trope model, as on mine, mental states are 
not identical to physical states. ${ }^{39}$ I do not mean to suggest that I take physicalism to be a reason to reject trope-theory. My reasons for rejecting it are independent of the truth or falsity of physicalism. But the point might be of interest for those physicalists who would pin their hopes for token-identity theory on tropes.

Consider now the proposal that token states are facts or states-of-affairs. ${ }^{40}$ For this proposal to be helpful to the advocate of token-identity, it is not enough that (1) states are facts. It must also be the case that (2) facts are particulars, and that (3) facts are the kind of particular that is supposed to figure in token-identity claims. I do not think any of these conditions are satisfied: states are not facts, facts are not particulars, and, even if facts were particulars, they would not be the sort of particular that is supposed to figure in token-identity claims. Since a failure on any of these counts will dispose of this possibility, I will confine myself to the third point.

Even if facts were particulars, I contend, they would not be the sort of particulars that the proponent (or, for that matter, the opponent) of the doctrine of token-identity has in mind. For particulars, in the sense at issue in the debate over token-identity, are ontologically thick: they are potential instantiations of wholly distinct properties. But facts are not ontologically thick in this sense. ${ }^{41}$ The exemplification by a particular object of a physical property cannot be the state (i.e., the fact) that is the exemplification by that particular of a mental property. For facts (or in any case simple facts) are constituted by a single property possessed by an object (or a single relation that holds between more than one object). Different object, different fact. Different property, different fact. But if states are facts, and facts featuring different properties are distinct, then we should also say: Different property, different state. Thus, even if states were facts, and facts were particulars, they would not be the right sort of particulars, for they are not the sort of thing to be the instantiations of wholly distinct properties.

Physicalists who would identify states with facts may respond here by insisting that, even though mental properties are not physical properties, mental property instances or instantiations are identical to physical property instances or instantiations. In that sense, perhaps facts are ontologically thick, in the relevant sense. This option is worth exploring in more detail. For the present, I will only give initial expression to my failure to comprehend it. Consider a pair of (distinct) properties $\mathrm{p}$ and q. To say that these properties are distinct is to say, among other things, that what it is for an object to be $\mathrm{p}$ is different that what it is for an object to be q. But I fail to understand how one could maintain this while also insisting that an object's instantiating $\mathrm{p}$ could be the same as its instantiating $\mathrm{q}$. The claim that the relevant facts are identical, and thus that they have the ontological thickness characteristic of particularity, strikes me as a desperate measure. A fuller exploration of this proposal will, however, have to wait for another day.

\section{CONCLUSION}

Our discussion of tropes revealed one respect in which the upshot of this paper is hospitable to physicalism. If there are no token mental states, then physicalism 
is not threatened by the possibility of non-physical token states. But physicalism is less a thesis than a movement-indeed, it is a movement in search of a thesis. And sentences such as "mental states are nothing but physical states" have been dear to the heart of this movement, even if only in anticipation of finding something for these sentences to mean. To the extent that a physicalist is committed to interpreting them as asserting an identity claim, we have seen that she will be disappointed.

Nonetheless, other interpretations are possible. It is sometimes argued, for example, that physicalism does not require that mental state tokens are identical to physical state tokens, so long as the former are realized or constituted by the latter. ${ }^{42}$ Since the relata do not exist, however, this proposal fares no better than the token-identity thesis. A physicalist might turn instead to the thought that physicalstate types are realized by mental state types, where type-realization is explained in terms of some form of asymmetric dependence or supervenience. ${ }^{43}$ And this thought may be true. Should this count as vindication of the "nothing but" intuition? I leave that for others to decide.

It is not clear, however, why we ought to care about vindicating this intuition. The idea that a purely physical description of human beings omits some states need not augur a return to Cartesian Dualism. One does not thereby become committed to a new realm of (mental) objects, existing outside space and time, in which mental states inhere. The perfectly sensible notion that there must be some way of accounting for our capacity for thought in terms of the way our bodies are constructed can still be accommodated. And we can continue to accord to mental states the role in causal explanations that common sense assigns to them. ${ }^{44}$ Given how much the physicalist can keep without the identity thesis or the "nothing but" intuition, surrendering them should be relatively painless. ${ }^{45}$

\section{ENDNOTES}

1. See Putnam 1975 and Fodor 1973.

2. See, for example, Hill 1991.

3. See Marcus 2006.

4. Some have argued for similar theses. Dennett contends: "Folk psychology is abstract in that the beliefs and desires it attributes are not—or need not be — presumed to be intervening distinguishable states of an internal behavior-causing system" (1987, 52). But Dennett, as Thau points out, links the thesis that beliefs and desires are not particulars with the thesis that belief- and desire-attributions "are true only if we exempt them from a certain familiar standard of literality" (Dennett 1987, 72).

Hornsby and Steward on the contrary, clearly reject both the thesis that beliefs and desires are particulars and the thesis that particularity is a necessary condition of the reality of beliefs and desires. Hornsby's reasons for rejecting "the idea of discrete things combining (interacting?) in the production of action" in favor of "a network of intelligible dependencies between the facts about what an agent thinks, what she wants and what she does" $(1997,135)$, though plausible, are not as direct or decisive as they might be. She points out, correctly, that we in 
no way rely on the idea of mental states as particulars when we explain actions; and that by accepting this idea, we are faced with serious philosophical difficulties. In a similar vein, Steward holds that the intelligibility and motivation for the particular view of states derives from what she calls "the network model of causation," according to which "entities which are non-universal yet also stative in their nature must be amongst the causally productive items which combine in the generation of effects" $(2000,211)$. Steward argues extensively, and, in my view, effectively, against the network model of causation. (Steward, I should point out, conceives of the type-token relation somewhat differently than I do here. For Steward, but not for me, tokens are not necessarily particulars. This difference is not, in my view, a deep one.) In what follows, I outline a more direct assault on the notion of a token state, though one that is perfectly congenial to both Hornsby's and Steward's take on the issue.

Most recently, Thau argues forcefully against the particular conception of mental states, but does so not on the grounds that mental states are states but on the grounds that they are states of a special kind, they are "instantial," as opposed to "internal" states $(2002,60-62)$. Here I argue that states are, as such, not particulars. See also Collins 1987; Hunter 2001; and, in a different vein, Robinson 1990.

5. See Marcus 2001 and 2005.

6. A consequence of this approach is a limitation in the scope of my argument: It has no immediate implications for the doctrine that mental events are token-identical to physical events. Elsewhere, I argue that the doctrine of token-identity as applied to events is also false, though for different reasons. See Marcus 2006. This limitation should not be thought to make the conclusion of this essay's argument trivial. It still applies to all of what are commonly called the propositional attitudes: to beliefs, hopes, wishes, desires (though the status of desires as propositional attitudes is in my view dubious), suspicions, doubts, regrets, etc. If the doctrine of token-identity has no application to them, even if it does have application to mental events, the physicalist has a real reason to worry. For propositional attitudes are central instances of mental "things."

7. See Davidson 1980. This is not how Davidson formulates the paradox, but this formulation is equivalent. Combine the "Nomological Character of Causation" with his view that only physical laws are (strictly) nomological and you get "all causation is physical." Combine the (alleged) anomalousness of the mental with the nomologicality of the physical, and you (allegedly) get the impossibility of reduction.

8. According to a different way of cashing out the type-token distinction, tokens need not be particulars. On this conception, any determinate (e.g., scarlet) of a determinable (e.g., red) is a token of that type. This is not the conception of the token-type distinction that figures in debates over token-identity in the philosophy of mind.

9. On this conception of particularity, then, expressions such as 'some water' or 'a little gold' do not pick out particulars.

10. I also assume that the truth-makers for sentences such as ' $\mathrm{S}$ believes that $\mathrm{p}$ ' include mental properties. Some have recently challenged this assumption. See Armstrong 1980; Shoemaker 1980; and Heil 1998. I make this assumption for two reasons. First, I don't believe there are compelling reasons to reject the existence of mental properties. (I defend mental properties from the charge of epiphenomenalism in Marcus 2001 and Marcus 2005.) Second, I don't believe the Armstrong/Shoemaker/Heil proposal is much of an improvement over eliminativism. Boghossian puts the point well: "If there are extra-linguistic psychological 
properties for the sentences of physics to answer to, but no extra-linguistic properties for the sentences of psychology to answer to then it isn't true, in the strict and literal sense, that there are true sentences of psychology" (1990, 179-180).

11. See Galton 1984, chap. 2. Broadly construed, this way of distinguishing between states and events has been discussed in Ryle 2000; Kenny 1963; Vendler 1967; Mourelatos 1978; Dowty 1979; Bach 1981; Taylor 1985; Cresswell 1986; and Parsons 1990. See Penner 1970 for an illuminating discussion of its roots in Aristotle.

12. My discussion follows Galton 1984. For some other important discussions of verb-aspect, see Mourelatos 1978; Dowty 1979; Bennett 1981; and Parsons 1990.

13. On the view of events presented here, actions are events. (Action sentences admit of the perfective-imperfective distinction.) The view that actions are events was popularized by Anscombe 1957 and Davidson 1980. Among the dissenters is Bach 1980.

14. Also, as Galton persuasively argues, state-predications, such as "Jones believed that p" (in the ordinary sense), have a present tense version: "Jones believes that p." But eventpredications such as "Jones crossed the street" (or "Jones believed that p," in the sense of having finished believing that $\mathrm{p}$ ) have no present tense sense. "Jones is crossing the street" is not the present tense version of "Jones crossed the street"; rather it is the present tense version of "Jones was crossing the street." And although "James crosses the street" has a use, it is not used to say about the present what "James crossed the street" says about the past. See Galton 1984, 11-16.

15. See Ryle 2000; Kenny 1963; and Vendler 1967 for seminal developments in this way of thinking about events. I discuss the metaphysics of events, so understood, at length in Marcus 2006. See also note 11.

16. See note 6 above.

17. Galton 1984, 26.

18. It might be objected here that states, if they are universals, are not the sort of thing that can obtain for a stretch of time, or be broken down into sub-stretches of time. These qualities, it might be thought, must really belong to a particular instance (i.e., a token) of a state. But this is wrong. To say that a state obtains for a stretch of time is just to say that an object, in this case, Jones, exemplifies a universal, viz., believing that Nixon was a genius, for a stretch of time. And it is not the state that is broken down into sub-stretches of time, but the entire length of time over which it obtains that is so broken down. The state simply obtains during each of these sub-stretches.

19. It might be argued that not all events are countable. The following example was suggested by an anonymous referee. One could ask, "How many times has the universe expanded?" Perhaps the answers "just once" and "less than once" seem equally good. But expanding, like running, is not an event-rather, it is process. To specify something countable, the verb-phrase must provide a terminus: e.g., Jones ran a mile, Arthur crossed the street, the Colts defeated the Bears, etc. Once such a terminus is provided, our initial question can be answered. If the question asks how many times the universe has expanded amount a, then if it hasn't yet expanded amount a, the answer is "no times," and if it has already expanded amount a, then the answer is "one time." (And, of course, if has contracted and then reexpanded, then the answer may be some number greater than one.)

20. For a recent discussion and defense of four-dimensionalism, see Sider 2001. 


\section{See Wiggins 1980.}

22. See Dummett 1973, 547-548.

23. Gupta 1980, 2.

24. Dummett makes this point in slightly different terms. He says that someone who grasps the sense of a "substantive general term" (a term for a sortal) must know both the associated criterion of application and the associated criterion of identity; whereas someone who grasps the sense of an "adjectival general term" must know only the associated criterion of application, since there is no associated criterion of identity. (See Dummett 1973, 547-548.) Whereas Dummett speaks of criteria, I (following Gupta) speak of principles. A criterion of identity is (at least in Dummett's usage) primarily epistemic in character. A principle of identity, as Gupta puts it, is "the metaphysical counterpart of such an epistemic rule" (1980, 2). Since I am concerned with metaphysical issues, and not with epistemological ones, I have recast his point.

25. In distinguishing principles of identity from principles of individuation, I follow Castañeda 1975 and Savellos 1992.

26. I discuss this further in Marcus 2006.

27. I must say that I find this question very odd, but an anonymous referee for this journal thinks otherwise.

28. Galton 1984, 26-27.

29. See Wiggins 1980 and Lowe 1989 for illuminating discussions of the relationship between kind-membership and identity questions.

30. It might be objected here that there really are reds, viz., scarlet, crimson, etc. Even if this were true, however, it would be beside the point. For scarlet, crimson, and the like, are not particulars.

31. Mourelatos 1978. Steward 2000 also brings the argument of this paper to bear in her discussion of states, albeit to different effect.

32. Thau 2002, 62-68 also makes this point.

33. There is a related objection to the argument of section II that I don't take up here, as it would take us too far a field. According to a broadly Davidsonian tradition, the best semantics for what we have here isolated as event-sentences understands them as involving implicit quantification over particular events. (Following Parsons, we can call this the underlying event view.) According to philosophers who follow Davidson, this is, among other things, the best way to account for inferences from sentences such as 'Mary crossed the street briskly while whistling' to 'Mary crossed the street.' One might think — wrongly, in my view- that a parallel argument could be constructed for the underlying state view. According to this argument, the best semantics for what we have here isolated as state-sentences understands them as involving implicit quantification over particular states. Parsons 1990 considers this question in some detail. Though he roots for the underlying state view (no doubt in part because it coheres nicely with the underlying event view which is his primary focus), he admits the evidence for it is less than compelling. See chapter 10.

34. Galton 1984, 24.

35. Among the important works on tropes are Stout 1923; Williams 1953; and Campbell 1981. 
36. Since one motivation for trope-theory is the rejection of universals, some trope-theorists will deny that the two cars have anything in common, strictly speaking.

37. I remind the reader that the problem I raise here for tropes has no parallel for objects. For in the case of objects, the required non-arbitrary identity conditions are supplied by the principles of identity for the sortals or kinds of which the objects are instances.

38. Campbell admits as much in his 1983. Bennett 1988, however, argues that the thesis of token-identity is trivially true, since every mental trope is part of a fusion of mental and physical tropes, and these fused tropes are both mental and physical-they are instances of both mental and physical properties. Even if we accept the existence of these fusions, however, there are still, on Bennett's view, so far as I can tell, instances of mental properties that are not identical to instances of physical properties—viz., the mental and physical instances that compose the mental-physical fusions. Thus, his claims to the contrary notwithstanding, Bennett is an opponent of the doctrine of token-identity. He is committed to denying that every token mental state is identical to some physical state.

39. In fact, trope theory is even more hostile to physicalism than the view proposed here. For trope-theory would require that we admit large classes of non-physical particulars, corresponding to all of the real, non-physical properties. On my view, however, since there are no state tokens, there are no non-physical mental-state tokens. From the physicalist's perspective, then, trope-theory is even more abhorrent than the view I here advocate. Thus the appearance of wiggle-room created by the hypothesis that states are tropes is in any case not wiggle room for those who are the target of this essay. Trope-theory, if true, might save token states; but it would also doom the thesis that mental states are physical states.

40. I take facts to be actual states-of-affairs. The remarks offered here concerning facts apply equally well to states-of-affairs.

41. See Steward 2000 for a discussion of this point.

42. See, for example, Boyd 1980 and Tye 1996.

43. The literature on supervenience is vast; see Kim 1992 for seminal essays.

44. I defend these remarks extensively in Marcus 2001 and 2005.

45. Thanks to Ram Neta, Matti Eklund, Doug Lavin, Kelly Jolley, Michael Watkins, Guy Rohrbaugh, Roderick Long, Jim Stone, members of the Philosophy of Mind Workshop at the University of Chicago in 2004, an audience at Washington University in St. Louis, and two anonymous referees at this journal.

\section{BIBLIOGRAPHY}

Anscombe, G. E. M. 1957. Intention. Oxford: Blackwell.

Armstrong, D. M. 1980. A Theory of Universals. Cambridge: Cambridge University Press.

Bach, Emmon. 1981. “On Time, Tense, and Aspect: An Essay in English Metaphysics.” In Radical Pragmatics. Ed. Peter Cole. New York: Academic Press, 63-81.

Bach, Kent. 1980. “Actions are not Events.” Mind 89: 114-120. 
Bennett, Jonathan. 1988. Events and Their Names. Indianapolis: Hackett Publishing Company.

Bennett, Michael. 1981. "Of Tense and Aspect: One Analysis.” In Syntax and Semantics 14. Ed. Philip Tedeschi and Annie Zaenen. New York: Academic Press:, 13-30.

Boghossian, Paul. 1990. “The Status of Content.” The Philosophical Review 99: 157-184.

Boyd, Richard. 1980. "What Materialism Does Not Imply." In Readings in the Philosophy of Psychology. Ed. Ned Block. Cambridge, Mass.: Harvard University Press, 67-107.

Campbell, Keith. 1981. “The Metaphysics of Abstract Particulars.” In Properties. Ed. D. H. Mellor and Alex Oliver. Oxford: Oxford University Press, 125-139.

. 1983. "Abstract Particulars and the Philosophy of Mind." Australasian Journal of Philosophy 61: 129-141.

Castañeda, Hector Neri. 1975. "Individuation and Non-Identity: A New Look." American Philosophical Quarterly 12: 131-140.

Collins, Arthur. 1987. The Nature of Mental Things. Notre Dame: University of Notre Dame Press.

Cresswell, M. J. 1986. Why Objects Exist but Events Occur." Studia Logica 45: 371-375.

Davidson, Donald. 1980. Essays on Actions and Events. New York: Oxford University Press.

Dennett, Daniel. 1987. The Intentional Stance. Cambridge, Mass.: MIT Press.

Dowty, David. 1979. Word Meaning and Montague Grammar. Boston: Reidel.

Dummett, Michael. 1973. Frege: Philosophy of Language. Cambridge, Mass.: Harvard University Press.

Fodor, Jerry. 1973. "Special Sciences, or the Disunity of Science as a Working Hypothesis." Synthese 28: 97-115.

Galton, Anthony. 1984. The Logic of Aspect. Oxford: Clarendon Press.

Gupta, Anil. 1980. The Logic of Common Nouns. New Haven: Yale University Press.

Heil, John. 1998. Philosophy of Mind: A Contemporary Introduction. New York: Routledge.

Hill, Christopher. 1991. Sensations: A Defense of Type Materialism. Cambridge: Cambridge University Press.

Hornsby, Jennifer. 1997. Simple Mindedness. Cambridge, Mass.: Harvard University Press.

Hunter, David. 2001. "Mind-Brain Identity and the Nature of States." Australasian Journal of Philosophy 79: 366-376.

Kenny, Anthony. 1963. Action, Emotion and the Will. London: Routledge and Kegan Paul.

Kim, Jaegwon. 1993. Supervenience and Mind. Cambridge: Cambridge University Press.

Lowe, E. J. 1989. Kinds of Being. Oxford: Basil Blackwell.

Marcus, Eric. 2001. "Mental Causation: Unnaturalized, But Not Unnatural.” Philosophy and Phenomenological Research 63: 57-83.

__ 2005. "Mental Causation in a Physical World." Philosophical Studies 122: 27-50.

—_. "Events, Sortals, and the Mind-Body Problem." Synthese 150: 99-129.

Mourelatos, Alexander. 1978. "Events, Processes and States." Linguistics and Philosophy 2: 415-434. 
Parsons, Terence. 1990. Events in the Semantics of English. Cambridge, Mass.: MIT Press.

Penner, Terence. 1970. "Verbs and the Identity of Actions-A Philosophical Exercise in the Interpretation of Aristotle." In Ryle: A Collection of Critical Essays. Ed. Oscar P. Wood and George Pitcher. Garden City, NY: Doubleday, Anchor Books, 393-460.

Putnam, Hillary. 1975. "The Nature of Mental States." In Readings in the Philosophy of Psychology. Ed. Ned Block. Cambridge, Mass: Harvard University Press, 223-232.

Robinson, William. 1990. "States and Belief." Mind 99: 33-51.

Ryle, Gilbert. 2000 [1949]. Concept of Mind. Chicago:University of Chicago Press.

Savellos, Elias. 1992. "Criteria of Identity and the Individuation of Natural-Kind Events." Philosophy and Phenomenological Research 12: 807-831.

Sider, Theodore. 2001. Four-Dimensionalism: An Ontology of Persistence and Time. Oxford: Clarendon Press.

Steward, Helen. 2000. The Ontology of Mind. Oxford: Oxford University Press.

Stout, G. F. 1923. "Are the Characteristics of Particular Things Universal or Particular?" Aristotelian Society Supplementary Volume 3: 114-127.

Sydney Shoemaker. 1980. "Causality and Properties." In Time and Cause. Ed. Peter Van Inwagen. Boston: Reidel.

Taylor, Barry. 1985. Modes of Occurrence: Verbs, Adverbs and Events. Oxford: Blackwell.

Thau, Michael. 2002. Consciousness and Cognition. Oxford: Oxford University Press.

Tye, Michael. 1996. Ten Problems of Consciousness. Cambridge, Mass.: MIT Press.

Vendler, Zeno. 1967. Linguistics and Philosophy. Ithaca: Cornell University Press.

Wiggins, David. 1980. Sameness and Substance. Oxford: Basil Blackwell.

Williams, D.C. 1953. "On the Elements of Being: I." Review of Metaphysics 7: 3-18. 
